\title{
Sanitized human urine (Oga) as a fertilizer auto-innovation from women farmers in Niger
}

\author{
Hannatou O. Moussa ${ }^{1}$ (D) Charles I. Nwankwo ${ }^{2}$ - Ali M. Aminou ${ }^{3}$ - David A. Stern ${ }^{4}$ - Bettina I. G. Haussmann ${ }^{5}$. \\ Ludger Herrmann ${ }^{2}$
}

Accepted: 29 January 2021 / Published online: 29 July 2021

(C) The Author(s) 2021

\begin{abstract}
Poor soil chemical fertility and climate change restrict pearl millet grain yield in Niger Republic. Apart from the seedball technology, which targets majorly early phosphorus supply to the plants, the recommended practices of mineral fertilization and seed treatments (coating and priming) are barely affordable to the local farmers in particular. In the case of female farmers, who usually have chemically infertile farmlands often located far away from their homestead, low pearl millet grain yield can be exacerbated. In quest for a cheap, affordable, and effective solution, we hypothesized that the application of sanitized human urine (Oga), in combination with organic manure (OM) or solely, increases pearl millet panicle yield in women's fields and on different local soils. In on-farm large- $N$ trials $(N=681)$ with women farmers in two regions of Niger (Maradi, Tillabery), pearl millet panicle yields were compared between the control (farmer practice), and a combination of Oga and OM in the first and second year, and Oga alone in the third year. Our results showed an average panicle yield increase of about $+30 \%$, representing +200 to $+300 \mathrm{~kg} \mathrm{ha}^{-1}$. Major factors determining the yield effect are season, village, and local soil type. This study shows for the first time that Oga innovation can be used to increase pearl millet panicle yield particularly in the low fertile soils of women's farmlands in Niger. Oga innovation is affordable, locally available, and does not pose a risk to resource-poor female farmers of Niger.
\end{abstract}

Keywords Female farmers $\cdot$ Human urine $\cdot$ Sahelian West Africa $\cdot$ Organic fertilizer $\cdot$ Low fertile soils $\cdot$ Animal dung $\cdot$ Pearl millet

Dr. Nwankwo is affiliated with University of Hohenheim and thus eligible for publication with OA under the German Agreement.

Charles I. Nwankwo

c.nwankwo@uni-hohenheim.de

1 Department of Rainfed Crops (DCP), National Institute of Agricultural Research of Niger, Maradi, Niger

2 Institute of Soil Science and Land Evaluation, University of Hohenheim, Emil-Wolff Str. 12a, 70559 Stuttgart, Germany

3 Federation of Maradi Farmers' Unions, FUMA Gaskiya, Maradi, Niger

4 IDEMS International, Reading, UK

5 Institute of Plant Breeding, Seed Science and Population Genetics, University of Hohenheim, Fruwirthstr. 21, 70599 Stuttgart, Germany

\section{Introduction}

In Niger Republic, several challenges restrict the yield of the major staple crop - pearl millet (Pennisetum glaucum (L). R. Brown). These include low chemical soil fertility (Voortman 2010) as well as climate change aspects like unpredictable and highly variable rainfall amount and distribution (Sivakumar 1988). Proposed management options to tackle soil fertility include NPK-mineral fertilizer application in form of microdosing (Aune and Ousman 2011) or broadcast (Badiane et al. 2001), seed coating with pure phosphorus (Karanam and Vadez 2010), seed priming with Pseudomonas fluorescens (Raj et al. 2004), and the seedball technology (Nwankwo 2019). Apart from micro-dosing and seedballs, none of these technologies is easily affordable or has particularly addressed women farmers.

However, women play a significant role in sub-Saharan agriculture, e.g., contributing a higher share of labor to food production than men (Blackden et al. 2003). The economic 
empowerment of women has the potential to reduce poverty and to increase economic growth in sub-Saharan Africa. Despite this, specifically supporting their efforts has often been neglected (Chen 2008).

In contrast, in India, women empowerment significantly increased food production (Satyavathi et al. 2010). In Niger, men usually retain absolute right to land but can provide access to their spouses. Otherwise, women can have access to land through inheritance according to the most common traditional practice. Either purchasing or renting arable farmlands is also possible. But a higher percentage of women lack the financial resources to do so (Doss 2001). In Niger, according to Diarra and Monimart (2006), women at Jirataoua, a district in the south of Maradi region, lost access to their inherited lands due to land pressure for over six decades. A higher area of these farmlands was either developed into motor accessible roads, traditional recreational sites, or houses (including mosques) that were constructed to meet accommodation demand for the increasing population. At Dungu in the south Zinder region, up to date, women have full access to land often granted by their husbands. But these farmlands belonging to women are often located far away from the settlements; and often show absolute phosphorus deficiency levels caused by the fact that they receive less manure input. The direct consequence of the low chemical soil fertility level is low panicle yield, usually $<400 \mathrm{~kg} \mathrm{ha}^{-1}$ (Nwankwo 2019).

In several countries including central Niger at the beginning of the cropping season, spouses mandatorily first have to help their husbands (Safilios-Rothschild 1985) to install the major staple crops. As a result, women can take care of their farmlands only later in the season. However, late planting reduces the potential crop yield (Reddy and Visser 1993), simply due to a shortened growth period in seasonal climates as well as leached nutrients with high intensity rains at the beginning of the season. This is particularly true in semi-arid regions like the Sahel, where the vegetation period is per se extremely short (i.e., $\leq 90$ days). For these reasons, it makes sense to focus more on management options that support women. Therefore, since 2012, the Farmer FederationFUMA Gaskiya (Fédération des Unions de Producteurs de Maradi Gaskiya) has been leading a research project funded by the McKnight Foundation's Collaborative Crop Research Program that specifically aimed at increasing the productivity of women-managed agricultural fields in the Maradi and Tillabery regions of Niger.

African women are less likely to adopt innovations due to lack of access to information and the required resources, and partially due to lower decision-making power (Doss 2001). An important question is: what characteristics should innovation targeting women farmers possess in order to increase the chances of adoption? They should be (i) easy to apply, (ii) effective, (iii) based on local resources, (iv) accessible, and (v) bear low transport costs and economic risks. In addition, innovations should not be in contradiction to the cultural and religious habits and beliefs of the target people. Considering all these pre-requisites, the seedball technology seems to fit quite well apart from workload associated with its mass production. However, this technology particularly targets phosphorus nutrient enhancement (Nwankwo et al. 2018). In most Sahelian sandy soils (Arenosols according to the WRB (2015)), multiple nutrient deficiencies occur (Voortman 2010) that can best be counteracted by organic fertilizer that are per se containing a multitude of plant nutrients. Therefore, a cheap, simple, and effective holistic approach to mitigate the low chemical fertility status of women's fields could be the application of sanitized human urine in combination with organic manure $(\mathrm{OM})$. The urine would mainly supply nitrogen and potassium, while the OM would add other nutrients including some phosphorus. Urine application has already shown to increase yield of different crops in sub-Saharan Africa and elsewhere on the globe (e.g., Karak and Bhattacharyya 2011). In order to assess whether the application of sanitized urine is culturally feasible, the farmer federation-FUMA Gaskiya engaged in a process to assess the option of using human urine as fertilizer in an inclusive and cultural-sensitive manner.

The objective of this study was to optimize, introduce, and test the application of human urine, partially in combination with OM, with female farmers in south-central and south-west Niger. Human urine was of special interest, since (i) it provides readily available nitrogen that is supposed to be the major limiting nutrient in the soils of the intervention regions apart from phosphorus, (ii) the resource is readily available to all households, even the poorest, (iii) according to religious leaders its use is not constrained, and (iv) it is an autoinnovation that was developed in the region by the farmer federation-FUMA Gaskiya. In order to reduce the cropping risk, human urine was first combined with OM and later tested as sole treatment. We hypothesized that (i) the application of human urine, in combination with OM or solely, increases pearl millet panicle yield in women's fields and on different local soils and (ii) human urine application as an innovation is compatible with the management practices of the female farmers.

\section{Material and methods}

\subsection{Research environment}

In order to increase adoption rates, the compatibility of an innovation with the culture of the target people is crucial (Guglielmino et al. 1995). Involving the farmers as early as at the stage of innovation development in order to make any necessary adjustments (Herrmann et al. 2013) is useful, too. Therefore, women farmers were reached through their 
federation-FUMA Gaskiya that has tradition in collaboration with several research institutes.

\subsection{The story of "Oga" development at the farmer federation-FUMA Gaskiya in Niger Republic}

FUMA Gaskiya (Federation of Maradi Farmers' Unions) is a farmers' organization comprising over 12,000 members. More than $52 \%$ of its members are women. FUMA aims at strengthening the productivity and entrepreneurial capacities of its members. Since 2002, the major partners of FUMA are (i) National Institute for Agronomic Research, NigerINRAN, (ii) International Crops Research Institute for the Semi-Arid Tropics-ICRISAT, and (iii) University of Hohenheim, Germany. FUMA conducts on-farm research since its establishment till date but carved out the "Women's field project" in 2012 to particularly target women farmers in rural areas of Maradi region, Niger Republic. It aims at improving the welfare of women and their respective households using low-cost agro-ecological intensification options (AEI). The use of sanitized human urine locally known as "Oga" is one of the AEI options. Oga means "the boss" in Igbo language, an ethnic group in south-east Nigeria. Oga is commonly used in Nigeria in public and government offices to show respect to someone in a position of authority. Because urine application is seen as a taboo among some ethnic groups like Peulh, the name Oga was proposed by a farmer as replacement. Therefore, the term Oga is not an abbreviation, and will be used in the following. At first most farmers were reluctant about Oga application due to religious and sanitary reasons. To convince farmers to test and apply Oga, the project team encouraged farmers to combine Oga with organic wastes and dung in the first and second year of the project. These local farmers, having seen positive results, were convinced to apply solely Oga in subsequent years. Formal discussions were held with religious leaders and medical experts on the stand of Koran and sanitary aspects, respectively. Cultural and social aspects of Oga were discussed. In general, Oga has neither religious, cultural, social, nor sanitary barriers. A video clip was projected in selected villages, shared through WhatsApp and YouTube platforms to create awareness about the positive effects of Oga and its general acceptance. This story is documented online in a video (www.youtube.com/watch? $\mathrm{v}=$ 0WpGKK7roZ4\&vl=fr) (Fig. 1).

The on-farm trials were conducted in Niger Republic from 2014 to 2016. Field trials were installed in two regions: Maradi in south-central and Tillabery in the south-west Niger. Maradi is represented by two intervention zones and Tillabery by one (see Table 1). Both regions are characterized by one cropping season of about 3-month length (Fig. 2), usually starting in June and lasting until the end of September. Rainfall is often poorly distributed over time and space with intermittent dry spells, and a range of 20-35 rainfall days per year (Sivakumar 1988).

According to the WRB (2015), the dominant soil type in both regions is Arenosol. This extremely sandy soil has a low organic matter content and extremely low chemical fertility, but has a high infiltration rate and is easy to till (Klaij and Vachaud 1992). The results of a pre-investigation at Warzou village in the Maradi region showed that female farmlands are usually distant from the settlement and receive less nutrient replenishment, and thus are characterized by a low soil nutrient status (Nwankwo 2019).

\subsection{Field trial design}

Prior to the planting seasons of 2014 and 2015, women farmers and local animators, i.e., the contact persons engaged by the farmer organization, were trained on how to collect, store and apply Oga. In 2014 and 2015, Oga and OM were jointly applied as post-emergence treatment. The combination of Oga and OM was deliberate because some farmers already used OM on their fields as nutrient source in order to increase yield. Opting to apply solely Oga at the beginning of the trial series could have discouraged the farmers from accepting "Oga" as an innovation due to the cropping risk associated to this unknown innovation. For this reason, the combination of Oga and OM was tested in the first 2 years, whereas only Oga was the tested treatment in 2016.

In 2014 and 2015, the trial plot area was exactly $100 \mathrm{~m}^{2}$ (i.e., 100 planting pockets with a $1 \mathrm{~m} \times 1 \mathrm{~m}$ planting distance). But in 2016, it ranged between 100 and $400 \mathrm{~m}^{2}$ depending on farmers' decision. A total of 159, 288, and 234 on-farm trials were conducted in the years 2014, 2015, and 2016, respectively (see Table 1). The following context variables differed among the individual trials: weed management, local soil type, and social class of the women farmer who conducted the test. Weed management (partial weeding versus full weeding at the first weeding date) was considered in 2014 and 2015, only. Partial weeding comprises weeding around the plant pocket or along the planting ridge during the first weeding, while leaving the weeds on the adjacent surfaces. At the second weeding, full weeding is carried out. Advantages of partial weeding include (i) reduction of weeding time, i.e., less labor demand, (ii) soil fertility improvement through anti-leaching, and (iii) protection of young seedlings against windstorms at the beginning of the season. Weeding was carried out manually as it is the usual local farmer practice. The first weeding was done about 2 weeks after planting, while the second often follows again 2-3 weeks later. The third weeding, where necessary, is often randomly done depending on farmers' personal decision. However, the same weeding practice was applied to both control and treatment plots.

Local soil type and women's social class as factors were considered from 2014 to 2016 . Farmers differentiate a number 


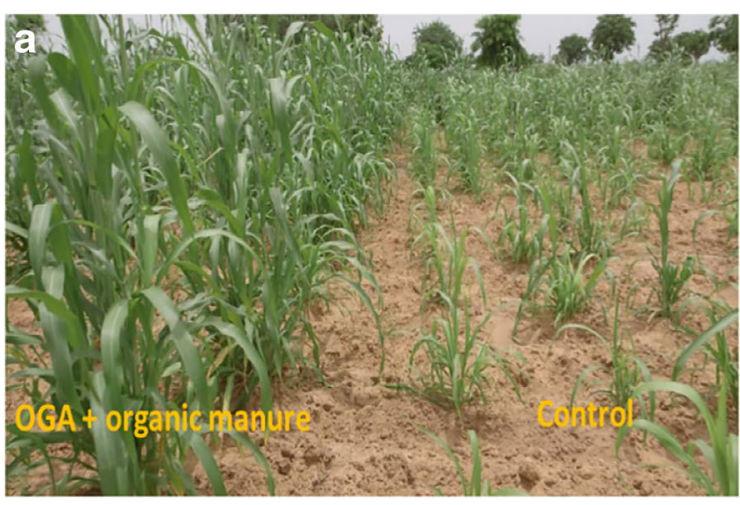

Fig. 1 Fields of pearl millet treated with post-emergence application of (a) sanitized human urine (Oga) and organic manure (OM) 42 DAS on a $10 \mathrm{~m} \times 10 \mathrm{~m}$ area in 2015 and (b) solely Oga 29 DAS on a $5 \mathrm{~m} \times 20 \mathrm{~m}$ area in 2016, compared to the control at Maradi, Niger Republic. OM was

of local soil types. Jigawa as preferred crop land has a sandy texture, is widely spread in the two intervention regions, and the preferred pearl millet cropping site. However, it is sensitive to wind erosion with a tendency to crust formation at the surface. Jigawa is characterized by low chemical fertility and low organic matter content, but high potential infiltration rate (Yamba 1993). Gueza contains slightly more fine elements (silt and clay) that make it compact leading to a comparably lower infiltration rate. Once Gueza is devoid of its vegetation cover, it is exposed to water erosion. Sorghum (Sorghum bicolor) shows a higher crop share on this local soil type. GuezamiGuezami is an intermediate soil between Jigawa and Gueza. It has sandy surface texture and gets harder with depth. Jampali is a sandy reddish soil that farmers consider as the least fertile one (an effect probably caused by $\mathrm{Al}$ toxicity), mainly cropped with cowpea (Vigna unguiculata). Damba has a similar texture as Gueza and is considered the most fertile soil by farmers since it receives additional water by lateral flow due to its position in micro-topographic lows. However, inundations can happen.

The three social classes differentiated by farmers themselves were (i) young women, (ii) elderly women with help,

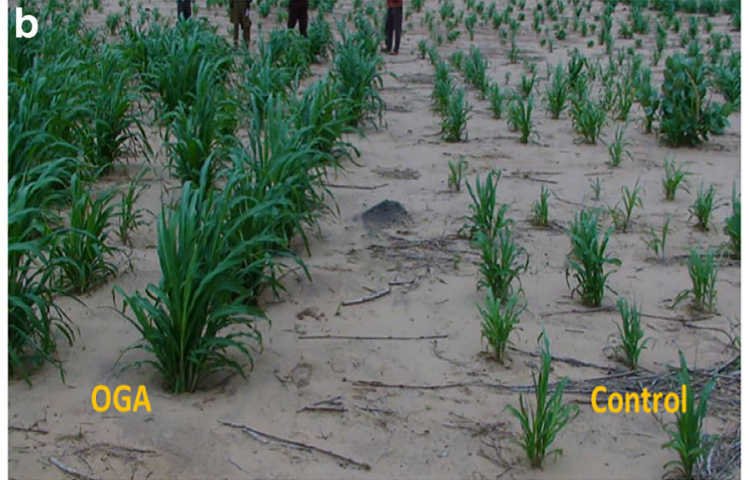

applied during sowing at the rate of $1 \mathrm{~kg}$ per planting hill at a hill spacing of $1 \mathrm{~m} \times 1 \mathrm{~m}$ where Oga was applied 14 DAS at the rate of 0.21 per plant pocket. DAS days after sowing.

and (iii) without help. "Help" among social class indicates access to financial resources to hire labor. "Young" refers to the newly married women who may or may not have children. These children cannot provide farm labor because of their tender age. These young women carry out most of the farming activities by themselves with or without support from their husbands. "Young" women farmers are generally more active.

\subsection{Material collection, preparation, storage, and application}

The pearl millet variety used in this study was ICMV IS 89305. It is an open-pollinating variety that was bred by ICRISAT-Niger from the crossing of HK B-78, Souna-3, and CIVT. It usually flowers at 70 days after sowing (DAS) and matures at 90-100 DAS. It is resistant to downy mildew (Sclerospora graminicola) and stem borer (Coniesta ignefusalis). Under good management practices, the grain yield can be as high as $2000 \mathrm{~kg} \mathrm{ha}^{-1}$. It has a thousand grain mass (TGM) of about $10 \mathrm{~g}$. Farmers in Maradi and Tillabery regions of Niger have adopted this variety on parts of their fields.

Table 1 An overview of the regional experimental setting from 2014 to 2016 in Niger Republic. ${ }^{\mathrm{a}}$ For the precise number of trials per village please refer to Table 2.

\begin{tabular}{|c|c|c|c|c|c|c|c|}
\hline \multirow[b]{2}{*}{ Region } & \multicolumn{2}{|c|}{$2014(N=159 \text { trials })^{\mathrm{a}}$} & \multicolumn{2}{|c|}{$2015(N=288$ trials $)$} & \multicolumn{3}{|c|}{$2016(N=234$ trials $)$} \\
\hline & Maradi & Tillabery & Maradi & & Maradi & & Tillabery \\
\hline Intervention zone & Maradi North & Tillabery & Maradi North & Maradi South & Maradi North & Maradi South & Tillabery \\
\hline Site & Serkin Haussa & Say & Serkin Haussa & Safo & Serkin Haussa & Safo & Say \\
\hline \multirow[t]{3}{*}{ Village } & Arraouraye & Bokki & Arraouraye & Garin Labo & Arraouraye & Garin Labo & Bokki \\
\hline & Dan Banga & Tchela & Dan Banga & Garin Mai Gari & & Garin Mai Gari & Tchela \\
\hline & \multicolumn{2}{|l|}{ Dan Tsunsu } & \multicolumn{2}{|l|}{ Dan Tsunsu } & & Gade Iyya & Djangore \\
\hline Treatment & \multicolumn{2}{|c|}{ Control versus Oga $+\mathrm{OM}$} & \multicolumn{2}{|c|}{ Control versus Oga $+\mathrm{OM}$} & \multicolumn{3}{|c|}{ Control versus Oga } \\
\hline Plot size & \multicolumn{2}{|l|}{$100 \mathrm{~m}^{2}$} & \multicolumn{2}{|l|}{$100 \mathrm{~m}^{2}$} & \multicolumn{3}{|c|}{$\begin{array}{l}\text { Varied between } 100 \text { and } 400 \mathrm{~m}^{2} \\
\text { (farmers' choice) }\end{array}$} \\
\hline
\end{tabular}


Fig. 2 Rainfall for Maradi (a) and Tillabery (b) regions in Niger Republic for the cropping years 2014-2016. Values represent the amount of rainwater collected with pluviometers hung $1.5 \mathrm{~m}$ above the ground in an open space with a minimum distance of $10 \mathrm{~m}$ away from trees. Data for (a) and (b) were respectively collected at INRAN station Maradi and ICRISAT Sadoré, Niger Republic.
Rainfall (mm)

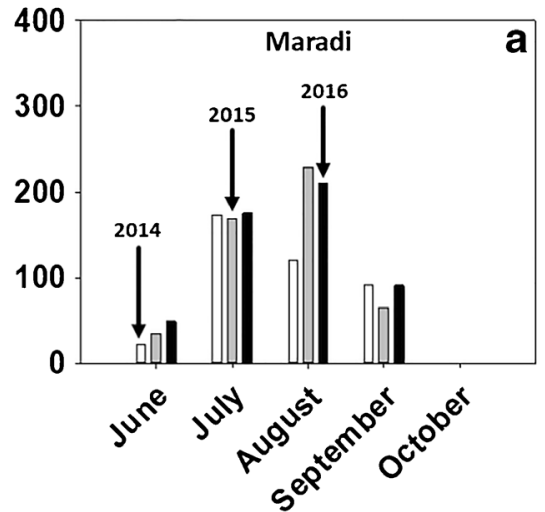

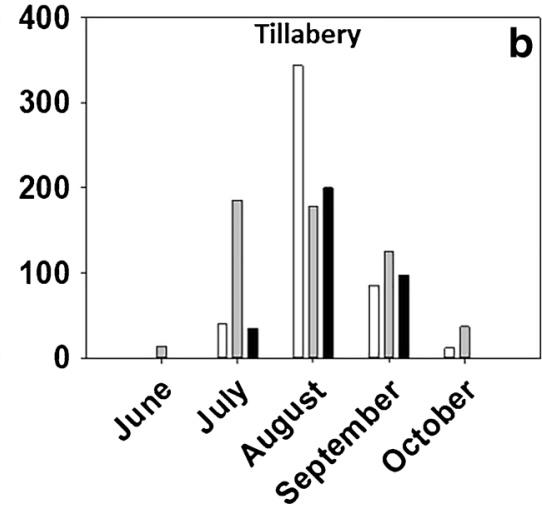

The OM used in the trials was made of animal dung cumulatively collected and stored 6-7 months prior to each season's onset. The animal dung originated mainly from sheep and goats, and a little amount from cattle. OM was applied during sowing at the rate of $1 \mathrm{~kg}$ per planting hill, i.e., 10 tons per hectare at a hill spacing of $1 \mathrm{~m} \times 1 \mathrm{~m}$. It was intended to have adequate amount of OM per pocket that can positively influence yield. Therefore, this rate was not based on any scientific recommendation. Wet sowing was applied, i.e., sowing when a first single rainfall reaches at least $20-25 \mathrm{~mm}$.

Oga is an innovation developed by the farmer federationFUMA Gaskiya. The human urine is collected in small plastic containers and transferred to bigger containers where it is stored for sanitation purposes at least 2-3 months before field application. Storing urine under a temperature range of 22-24 ${ }^{\circ} \mathrm{C}$, i.e., similar to the ambient temperature in Niger, leads to sanitization (Nordin et al. 2013). The resulting Oga is applied twice during the rainy season, i.e., at 14 and 35 DAS; these timings represent the establishment and booting stage of the crop, respectively. Oga is either applied without dilution or diluted with water in a ratio 1:1 depending on the soil moisture condition. When the soil moisture is adequate non-diluted, Oga can be applied at the rate of 0.21 per pocket. Under relative dry soil conditions application rate is 0.41 (i.e., $1: 1$ diluted) per pocket. The dilution of Oga most likely reduces the chances of ammonia escape via evaporation and its toxicity to plant roots on direct contact in particular under dry soil condition. Due to a large sample number, the chemical composition of the Oga used in this study was not measured, assuming an average content of $2.5 \mathrm{~g} \mathrm{~N}, 0.2 \mathrm{~g} \mathrm{P}, 1.0 \mathrm{~g} \mathrm{~K}$, $1.5 \mathrm{~g} \mathrm{Mg}, 15.0 \mathrm{~g} \mathrm{Ca}$, and $0.2 \mathrm{~g} \mathrm{Fe}$ per liter human urine (Kirchmann and Pettersson 1995); this means an approximate dose of $0.5 \mathrm{~g} \mathrm{~N}, 0.04 \mathrm{~g} \mathrm{P}, 0.2 \mathrm{~g} \mathrm{~K}, 0.3 \mathrm{~g} \mathrm{Mg}, 3.0 \mathrm{~g} \mathrm{Ca}$, and $0.04 \mathrm{~g}$ Fe per planting pocket and application. Calculating this input for two applications and on a hectare basis, it amounts to $10.0 \mathrm{~kg} \mathrm{~N}, 0.8 \mathrm{~kg} \mathrm{P}, 4.0 \mathrm{~kg} \mathrm{~K}, 6.0 \mathrm{~kg} \mathrm{Mg}, 60.0 \mathrm{~kg} \mathrm{Ca}$, and $0.4 \mathrm{~kg}$ Fe per hectare if we apply a planting density of 1 pocket per square meter.
In 2014 and 2015 planting season, pearl millet was grown in the women fields under rain-fed conditions. The treatments in 2014 and 2015 were (i) control, i.e., the zero application of fertilizer or farmer practice per se and (ii) Oga + OM. But in 2016, the farmers opted for sole application of Oga; therefore, (i) control and (ii) Oga served as the treatments. The panicle weight, as an appropriate productivity determinant for the farmers, was measured at harvest. Panicle yield data are highly correlated to grain yield (Nwankwo et al. unpublished), and easier to measure with usually a lower error variance.

\subsection{Statistical analyses}

In all the field trials, the trial units (famers' fields) were considered as treatment units. All collected data were first cleaned and tested for uniformity. Variance homogeneity and distribution were tested using Shapiro-Wilk test and Levene test, respectively. As the collected data were not evenly distributed due to large variations arising from field and location factors, Welch's one-way analysis of variance (ANOVA) was performed using Proc GLM separately per year for the three trial years. Where the ANOVA was significant (Tukey test at 5\% level), treatment means were compared for differences. To evaluate the relationship between panicle yield and the tested factors (location and soil type), Spearman's correlation model was applied. Results are presented as treatment means in tables and box plots. All statistical analyses and graph plotting were performed with SAS version 9.4 and Sigma Plot 13.0.

\section{Results and discussion}

\subsection{Average Oga treatment effects in the on-farm trials}

In all 3 years and across all on-farm trials conducted, the treatment (Oga + OM in 2014 and 2015, Oga solely in 2016) resulted in a positive and significant yield effect 
(2014: $+254 \mathrm{~kg} \mathrm{ha}^{-1}, 2015:+193 \mathrm{~kg} \mathrm{ha}^{-1}, 2016:+288 \mathrm{~kg}$ ha ${ }^{-1}$, Fig. 3).

The control yield differed not only due to inter-annual climate differences (Fig. 2) but also due to the fact that different sites and villages contributed to the testing in the different years (Table 1). The low coefficient of variation in 2015 in contrast to 2014 is probably forced by the fact that only sites in Maradi region were sampled. Since the average treatment effect is positive and of similar magnitude in all 3 years, we can assume that the major effect is triggered by the Oga application that delivers, in contrast to $\mathrm{OM}$, readily available, i.e., water-soluble nutrients. This conclusion is supported by a multivariate analysis, where the treatment type appeared as insignificant variable $(F$ value $=1.870$, Prob. $=0.173)$.

In tendency, the relative yield effect of the Oga $(+\mathrm{OM})$ application decreased with increasing control yield (Fig. 4, Table 2 sites Serkin Haussa and Say). Since a 3-year data were used here that represent the climatic variability, the control yield is interpreted as a major function of the chemical soil fertility. However, factors such as planting time and previously grown crops (legumes vs cereals) may affect the productivity levels in general.

Only in the relatively high yielding Dan Tsunsu village in 2014 (i.e., the two data points each with an arrow), the average Oga $(+\mathrm{OM})$ treatment effect was insignificant. In all other village-year combinations, the Oga $(+\mathrm{OM})$ technology was, on average, efficient and did neither present a risk for the yield nor for the monetary investment. It appears that up to a level of about $1000 \mathrm{~kg} \mathrm{ha}^{-1}$ panicle yield, the Oga technology can be recommended without hesitation. Above this threshold, the yield effect is facultative and other fertilizer strategies might be more promising.

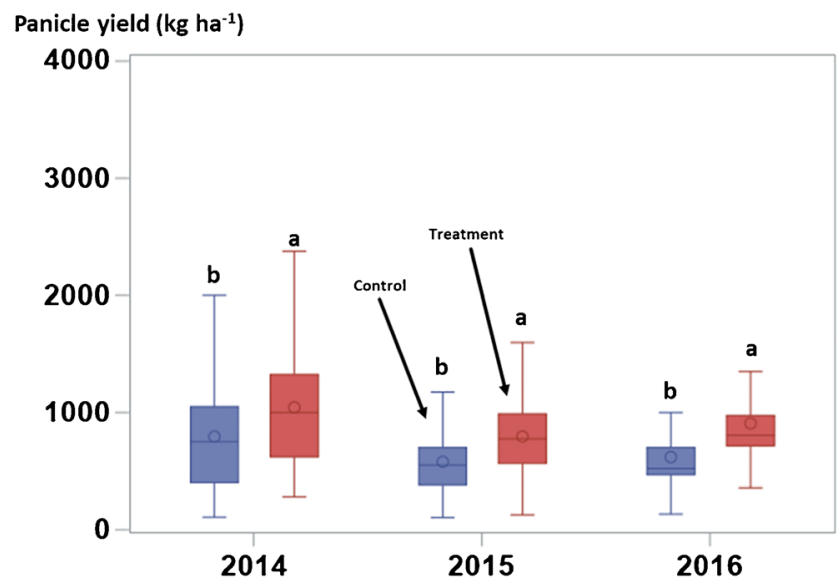

Fig. 3 Pearl millet panicle yield as affected by treatment over all test sites in Niger Republic and the period 2014-2016. Control = farmer practice, i.e., non-fertilized pearl millet; Treat $=$ treatment for 2014 and 2015 was post-emergence application of Oga (sanitized urine) + O.M (organic manure) and in 2016 Oga alone. Symbols show arithmetic means and error bars indicate standard deviations $( \pm)$, and different letters indicate significance (Tukey test at $5 \%$ level), computed separately for different years.
This view is deepened by Fig. 5, presenting the single observation points. While in 2014 still a relative high number of trials ended up with a failure (24\%), this changed with increasing experience of the animators and participating women farmers in on-farm testing to a negligible amount $(\leq 2 \%$ in 2015-2016).

The major problem in 2014 was that not all women farmers strictly followed the experimental protocol and applied to the control other additional management measures than to the treatment plot. This has to be taken into account when interpreting the 2014 data. Looking at the 2015 and 2016 data (Fig. 5), the rare cases where the Oga (+OM) treatment effect was significantly negative appear to be in the higher yielding environments (> $1000 \mathrm{~kg} \mathrm{ha}^{-1}$ panicle yield).

The 3-year aggregated means show for Serkin Haussa (driest site, wide-spread sandy soils) the lowest average panicle yield (Table 2). Control yield and absolute yield effect of the OGA (+OM) treatment decrease consistently from 2014 to 2016. However, the relative treatment effect increases in the same course from $+26 \%$ to $+38 \%$.

The Safo site farther south receives more rainfall and has, due to geological reasons, more fertile soils. In contrast to Serkin Haussa, all yield averages are higher, and absolute treatment effects increased from 2015 to 2016 with higher yield differences between villages in 2016. The relative yield increment is stable with about $40 \%$ difference in both years (Table 2).

The site Say lies about $500 \mathrm{~km}$ away. In contrast to the Maradi region (major ethnic group Haussa), settlers represent here a mixture of Djerma and Peulh people. The latter have easier access to animal manure due to their origin as herders. Soil conditions appear more variable. Climate is more comparable to Safo. Remarkable is the high yield for the Tchela village in 2014. Otherwise, the yield range is comparable to the Maradi region.

With respect to data variability, the sites distinctively differ. This is presented in Fig. 6 using the 2016 data. Bokki represents an example with a consistent low control yield on all fields, a distinct treatment effect, and a complete separation of control and treatment yields with small data spread within the treatments (Table 2). Arraouraye data, in contrast, show a distinctly smaller treatment effect but a higher spread within the treatments. Garin Mai Gari finally exhibits a high control yield, a distinct treatment effect, and a large absolute as well as relative data spread within the treatments.

Neither the number of observation points (Table 2) nor the soil diversity can directly explain these differences. Although the principally more fertile soil type Damba (in general higher $\mathrm{C}_{\text {org }}, \mathrm{N}_{\mathrm{t}}$, and CEC) occurs in Garin Mai Gari, it did not produce higher yields than the other soil types in that village. However, a study by Geiger (2017) showed that pearl millet control plot yields in the Maradi region were mainly and significantly explained by village (Spearman $r=0.77$ ) and local soil type (Spearman $r=0.41$ ). 
Relative yield increase (\%)

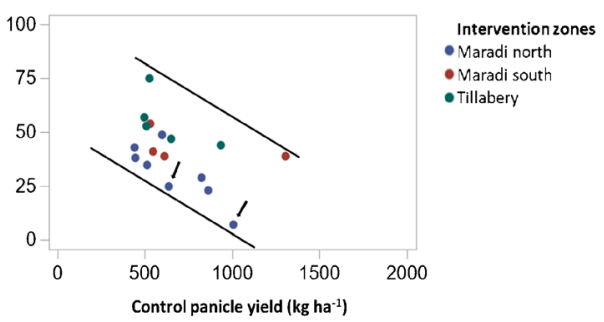

Fig. 4 Relative increase (\%) of the pearl millet panicle yield $\left(\mathrm{kg} \mathrm{ha}^{-1}\right)$ due to Oga $(+\mathrm{OM})$ treatment based on village level averages for years 2014 2016. Border lines (not statistically derived) indicate a visible inverse proportion trend. OM organic manure.

\subsection{Soil as a factor}

Looking at the global annual averages, the treatments lead for most soil types to an absolute yield increase in the order of 200-300 kg ha ${ }^{-1}$ (Table 3).
Judging 2014 as an average year with respect to rainfall, the control yields confirm the farmer judgment on productivity of the soils for pearl millet, i.e., Jigawa $>$ Gueza > Jampali. In that year, the treatment effect was highest on the soil with the lowest fertility (Jampali, Table 3 ). On the more loamy Gueza, soil treatment effects were positive but the lowest observed. In the more difficult year 2016, the treatment effects ranged between 244 and $323 \mathrm{~kg} \mathrm{ha}^{-1}$. In this case, the lowest absolute yield increase was recorded for the local soil type Jampali. Stating this, we must take into account that the total number of observation points as well as their relative shares changed between the years. This fact leads to limited interpretability and is a typical shortcoming of trials in diverse and uncontrollable environments.

With respect to soil effects in 2016 (Fig. 5), GuezamiGuezami and Jambali have an absolute yield limit at about $1000 \mathrm{~kg} \mathrm{ha}^{-1}$. Damba yields start where the former
Table 2 Pearl millet panicle yield, in $\mathrm{kg} \mathrm{ha}^{-1}$, as affected by treatment and trial site (region and village) for 2014-2016 planting seasons in Maradi (Serkin Haussa and Safo) and Tillabery regions (Say), Niger Republic. Values represent mean yield with coefficient of variation in brackets. Control farmer practice, i.e., no fertilization; $O M$ organic manure; $O g a$ sanitized human urine. Different letters indicate significance (Tukey test at 5\% level) and analyzed separately for different years.

\begin{tabular}{|c|c|c|c|c|c|c|c|}
\hline \multirow[t]{2}{*}{ Year } & \multirow[t]{2}{*}{ Region } & \multirow[t]{2}{*}{ Site } & \multirow[t]{2}{*}{ Village } & \multirow[t]{2}{*}{ Number of trials } & \multicolumn{2}{|c|}{ Panicle yield $\mathrm{kg} \mathrm{ha}^{-1}(\mathrm{CV})$} & \multirow[b]{2}{*}{ Increase due to treatment $(\%)$} \\
\hline & & & & & $\begin{array}{l}\text { Control (zero } \\
\text { fertilization) }\end{array}$ & $\begin{array}{l}\text { Oga treatment }(\mathrm{Oga}+\mathrm{OM} \text { in } 2014 \\
\text { and } 2015, \text { Oga only in 2016) }\end{array}$ & \\
\hline \multirow[t]{7}{*}{2014} & \multirow[t]{4}{*}{ Maradi } & \multirow[t]{4}{*}{ Serkin Haussa } & Arraouraye & 36 & $859^{\text {cd }}(40)$ & $1056^{\mathbf{c}}(45)$ & 23 \\
\hline & & & Dan Banga & 42 & $598^{\mathbf{e}}(70)$ & $892^{\mathrm{c}}(66)$ & 49 \\
\hline & & & Dan Tsunsu & 24 & $1004^{\mathrm{c}}(41)$ & $1071^{\mathbf{c}}(30)$ & 7 \\
\hline & & & Total/average & 102 & $786^{\mathrm{d}}(54)$ & $992^{\mathrm{c}}(51)$ & 26 \\
\hline & \multirow[t]{3}{*}{ Tillabery } & \multirow[t]{3}{*}{ Say } & Bokki & 27 & $646^{\mathrm{de}}(58)$ & $952^{\mathrm{c}}(42)$ & 47 \\
\hline & & & Tchela & 30 & $933^{\mathbf{c}}(58)$ & $1342^{\mathbf{b}}(36)$ & 44 \\
\hline & & & Total/average & 57 & $797^{\mathrm{b}}(61)$ & $1157^{\mathrm{a}}(42)$ & 45 \\
\hline \multirow[t]{7}{*}{2015} & \multirow[t]{7}{*}{ Maradi } & \multirow[t]{4}{*}{ Serkin Haussa } & Arraouraye & 80 & $513^{\mathbf{c}}(44)$ & $692^{\mathbf{b}}(38)$ & 35 \\
\hline & & & Dan Banga & 62 & $440^{\mathbf{c}}(41)$ & $629^{\mathbf{b}}(40)$ & 43 \\
\hline & & & Dan Tsunsu & 64 & $633^{\mathbf{b}}(38)$ & $793^{\mathrm{a}}(26)$ & 25 \\
\hline & & & Total/average & 206 & $528^{\mathrm{d}}(44)$ & $704^{\mathrm{b}}(38)$ & 33 \\
\hline & & \multirow[t]{3}{*}{ Safo } & Garin Labo & 74 & $608^{\mathbf{b}}(54)$ & $844^{\mathrm{a}}(45)$ & 39 \\
\hline & & & Garin Mai Gari & 8 & $547^{\mathbf{b c}}(68)$ & $772^{\mathbf{a b}}(17)$ & 41 \\
\hline & & & Total/average & 82 & $602^{\mathrm{c}}(55)$ & $837^{\mathrm{a}}(43)$ & 39 \\
\hline \multirow[t]{10}{*}{2016} & \multirow[t]{6}{*}{ Maradi } & \multirow[t]{2}{*}{ Serkin Haussa } & Arraouraye & 46 & $443^{d}(67)$ & $613^{\mathbf{b}}(51)$ & 38 \\
\hline & & & Total/average & 46 & $443^{\mathrm{d}}(67)$ & $613^{\mathrm{b}}(51)$ & 38 \\
\hline & & \multirow[t]{4}{*}{ Safo } & Garin Labo & 46 & $529^{\text {ef }}(38)$ & $813^{\mathbf{d}}(37)$ & 54 \\
\hline & & & Garin Mai Gari & 22 & $1302^{\mathbf{b}}(47)$ & $1815^{\mathbf{a}}(42)$ & 39 \\
\hline & & & Gade Iyya & 33 & $822^{\mathbf{d}}(30)$ & $1065^{\mathbf{c}}(26)$ & 30 \\
\hline & & & Total/average & 101 & $793^{\mathrm{b}}(57)$ & $1114^{\mathrm{a}}(52)$ & 40 \\
\hline & \multirow[t]{4}{*}{ Tillabery } & \multirow[t]{4}{*}{ Say } & Bokki & 25 & $524^{\mathrm{ef}}(5)$ & $921^{\text {cd }}$ (7) & 76 \\
\hline & & & Djangore & 30 & $493^{\text {ef }}(5)$ & $782^{\mathbf{d}}(11)$ & 59 \\
\hline & & & Tchela & 32 & $507^{d}(5)$ & $777^{\text {ef }}(5)$ & 53 \\
\hline & & & Total/average & 87 & $507^{\mathrm{cd}}(6)$ & $820^{\mathrm{b}}(11)$ & 62 \\
\hline
\end{tabular}


Treatment panicle yield ( $\left.\mathrm{kg} \mathrm{ha}^{-1}\right)$

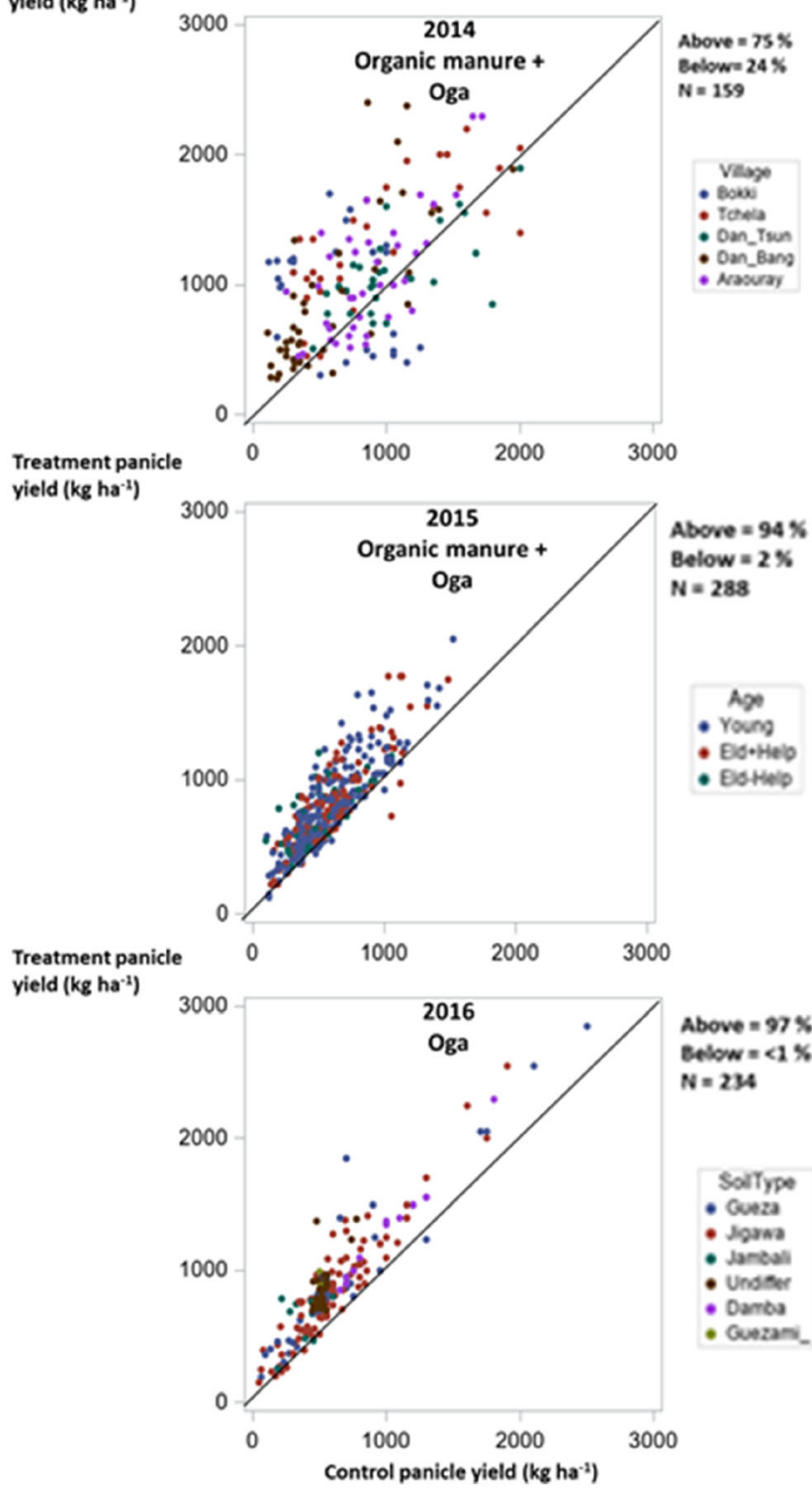

Fig. 5 Agronomic performance of the Oga (sanitized human urine) combined with OM (organic manure) (2014-2015) or sole Oga application (2016) as affected by village in 2014, women social class in 2015, and local soil type in 2016 over all sites in Niger Republic. Control $=$ farmer practice, i.e., no fertilization. Young $=$ age $<40$ years, Eld $=$ age $\geq 40$ years, Help $=$ human or financial resources; soil type $=$ local soil name.

ones cease. The most frequent soils-Jigawa and Guezashow an extreme widespread.

Another observation is that the treatment effect converges to about $30 \%$ panicle yield increase towards a higher number of observations (Fig. 7). This convergence effect is also visible for single soil types where a 3 -year data are available. The highest relative effect was achieved with the presumably least fertile soil (i.e., Jampali). Gueza, as preferred sorghum cropping site, shows lower relative yield increase than the other local soil types. The observations achieved $(\mathrm{N})$
Panicle yield (kg ha-1)

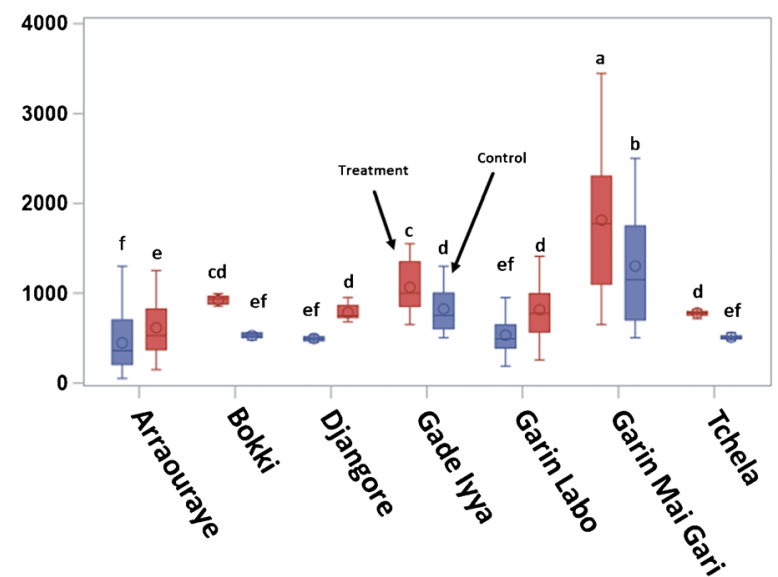

Fig. 6 Data spread of pearl millet panicle yield as presented by box plots for three exemplary sites in 2016. Dots represent single field panicle yields. Control $=$ farmer practice, i.e., non-fertilized pearl millet; Oga $=$ Oga (sanitized urine). Symbols show arithmetic means and error bars indicate standard deviations $( \pm)$, and different letters indicate significance (Tukey test at 5\% level).

somehow reflect the surface share of soils present in the intervention area, i.e., Jigawa > Gueza > GuezamiGuezami > Jampali $>$ Damba. These reasons in combination explain the convergence effect. A shortcoming was that not all farmers or animators were able to deal with the soil names. To that for a share of the data, yield information was collected but no soil names stated. Looking at the specific soil-related data, we conclude that, per soil type, a minimum of 50 observations should be collected. This is hardly achievable in most R4D environments.

Anyhow, this average of 30\% yield increase matches with data from other large-N trials (Nwankwo et al.—submitted) on low-level nutrient supplementation via seedballs to pearl millet in Niger.

\subsection{The effect of other contextual variables}

Age group, too, has an influence on the yield level (Fig. 8). Elderly women farmers without assistance harvest the lowest average yield and never attain the highest yield levels. This can be easily explained by the lower resource endowment, the lower available work force, and lower educational level. In contrast, young and elderly women farmers with assistance show a wide spread of yields, with the younger ones usually staying ahead.

Additional significant yield effects could be determined for the type of weed management (Fig. 8). Partial weeding, i.e., weeding only around the planting pockets during the first weeding phase (about 2 weeks after sowing), showed lower control yields in 2014 but an over-compensation under the Oga + OM treatment, leading to higher yields than the 
Table 3 The effect of local soil type and organic manure (OM) and/or sanitized urine (Oga) application on pearl millet panicle yield $\left(\mathrm{kg} \mathrm{ha}^{-1}\right.$, 2014-2016 seasons). Values represent mean yield with coefficient of variation in brackets, $N$ sample size. Control farmer practice, i.e., no fertilization; different letters indicate significance (Tukey test at 5\% level) and analyzed separately for different years.

\begin{tabular}{|c|c|c|c|c|c|}
\hline \multirow[t]{2}{*}{ Year } & \multirow[t]{2}{*}{ Local soil type } & \multirow[t]{2}{*}{ Number of trials } & \multicolumn{2}{|c|}{ Panicle yield in $\mathrm{kg} \mathrm{ha}^{-1}$} & \multirow[t]{2}{*}{ Increase due to treatment $(\%)$} \\
\hline & & & Control & $\begin{array}{l}\text { Oga treatment } \\
(\text { Oga }+ \text { OM in } 2014 \text { and } 2015, \text { Oga only in } 2016)\end{array}$ & \\
\hline \multirow[t]{5}{*}{2014} & Jambali & 20 & $740^{\mathrm{b}}(53)$ & $1130^{\mathrm{a}}(40)$ & 53 \\
\hline & Jigawa & 66 & $827^{\mathrm{b}}(51)$ & $1135^{\mathrm{a}}(45)$ & 35 \\
\hline & GuezamiGuezami & 31 & $761^{\mathrm{b}}(65)$ & $983^{\mathrm{ab}}(51)$ & 28 \\
\hline & Gueza & 32 & $806^{\mathrm{b}}(59)$ & $890^{\mathrm{ab}}(55)$ & 10 \\
\hline & Unknown & 10 & $678^{\mathrm{b}}(77)$ & $1070^{\mathrm{ab}}(51)$ & 58 \\
\hline \multirow[t]{4}{*}{2015} & Jambali & 8 & $355^{\mathrm{d}}(55)$ & $760^{\mathrm{ab}}(26)$ & 114 \\
\hline & Jigawa & 150 & $583^{\mathrm{b}}(45)$ & $778^{\mathrm{a}}(40)$ & 33 \\
\hline & GuezamiGuezami & 50 & $579^{\mathrm{bc}}(48)$ & $799^{a}(38)$ & 38 \\
\hline & Gueza & 80 & $487^{\mathrm{cd}}(50)$ & $637^{\mathrm{b}}(42)$ & 31 \\
\hline \multirow[t]{6}{*}{2016} & Jambali & 10 & $404^{\mathrm{e}}(40)$ & $648^{\mathrm{de}}(30)$ & 60 \\
\hline & Jigawa & 107 & $628^{\mathrm{de}}(58)$ & $904^{\mathrm{b}}(56)$ & 44 \\
\hline & GuezamiGuezami & 12 & $496^{\mathrm{e}}(3)$ & $819^{\text {bcd }}(13)$ & 65 \\
\hline & Gueza & 46 & $518^{\mathrm{e}}(11)$ & $849^{\mathrm{bc}}(18)$ & 64 \\
\hline & Damba & 44 & $648^{\mathrm{de}}(78)$ & $927^{\mathrm{b}}(62)$ & 43 \\
\hline & Unknown & 15 & $1007^{\mathrm{b}}(31)$ & $1295^{\mathrm{a}}(29)$ & 29 \\
\hline
\end{tabular}

complete weeding variant in both observation years. It appears that without nutrient amendment, the remaining weeds in the partial weeding plots exhibit a competition effect in years with lower rainfall.

Once nutrients are locally applied to the planting pocket to which the weeds have limited or no access, there can be a positive weed effect in the form of erosion control and seedling protection against sand storms, reducing the damaging effect of saltating sand grains on the young and tender seedlings (Michels et al. 1995) so that the latter can make full use of the fertilizer.

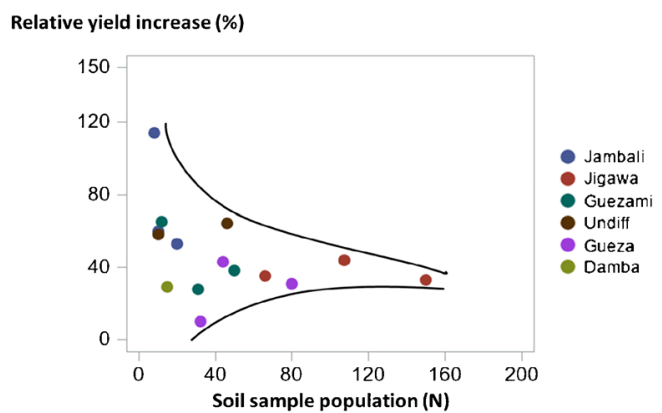

Fig. 7 Convergence of soil type-depending yield effect with larger sample population. The hyperbolic curves (not statistically derived) indicate a visible convergence trend. Guezami = GuezamiGuezami, Undiff $=$ undifferentiated

\subsection{Agronomic lessons learned from the field trials}

Reported yield levels are within the expected order of magnitude for on-farm trials (e.g., Bationo et al. 1992). After a first year (2014) of on-farm trials with highly variable Oga (+OM) treatment effects of ca $100 \mathrm{~kg}$ (Fig. 5), continued farmer training on how to correctly apply the trial protocol, treatment effects were throughout positive in the second and third year, i.e., in 2015 and 2016. Although also in the latter years' treatment effects showed certain variability, the global panicle yield increase ranged from +170 to $+313 \mathrm{~kg} \mathrm{ha}^{-1}$ for the final 2016 season. Although no other study on human urine application to pearl millet in Niger is scientifically documented, sheep urine application to pearl millet in Niger (Powell et al. 1998) and human urine application to sorghum in Ghana (Germer et al. 2011) in researcher trials showed even higher yield effects. Comparing the yield effects of sole Oga (applied in 2016) with combined application of OM and Oga (applied in 2014 and 2015) reveals that Oga is responsible for the main yield effect. This does not mean that solid organic manure application should be neglected, since SOM values are in general low $(<1 \mathrm{wt} \%)$ in the surveyed soils (Geiger 2017) and plant available phosphorus is absolutely deficient $(\leq 4 \mathrm{mg}$ $\mathrm{kg}^{-1}$ Bray1 P). The advantage of Oga application is, however, that the nutrients applied are directly available - in contrast to the ones in OM - and that the application of the fluid might help the plant during dry spells, as they often occur in the early 


\section{Panicle yield $\left(\mathrm{kg} \mathrm{ha}^{-1}\right)$}
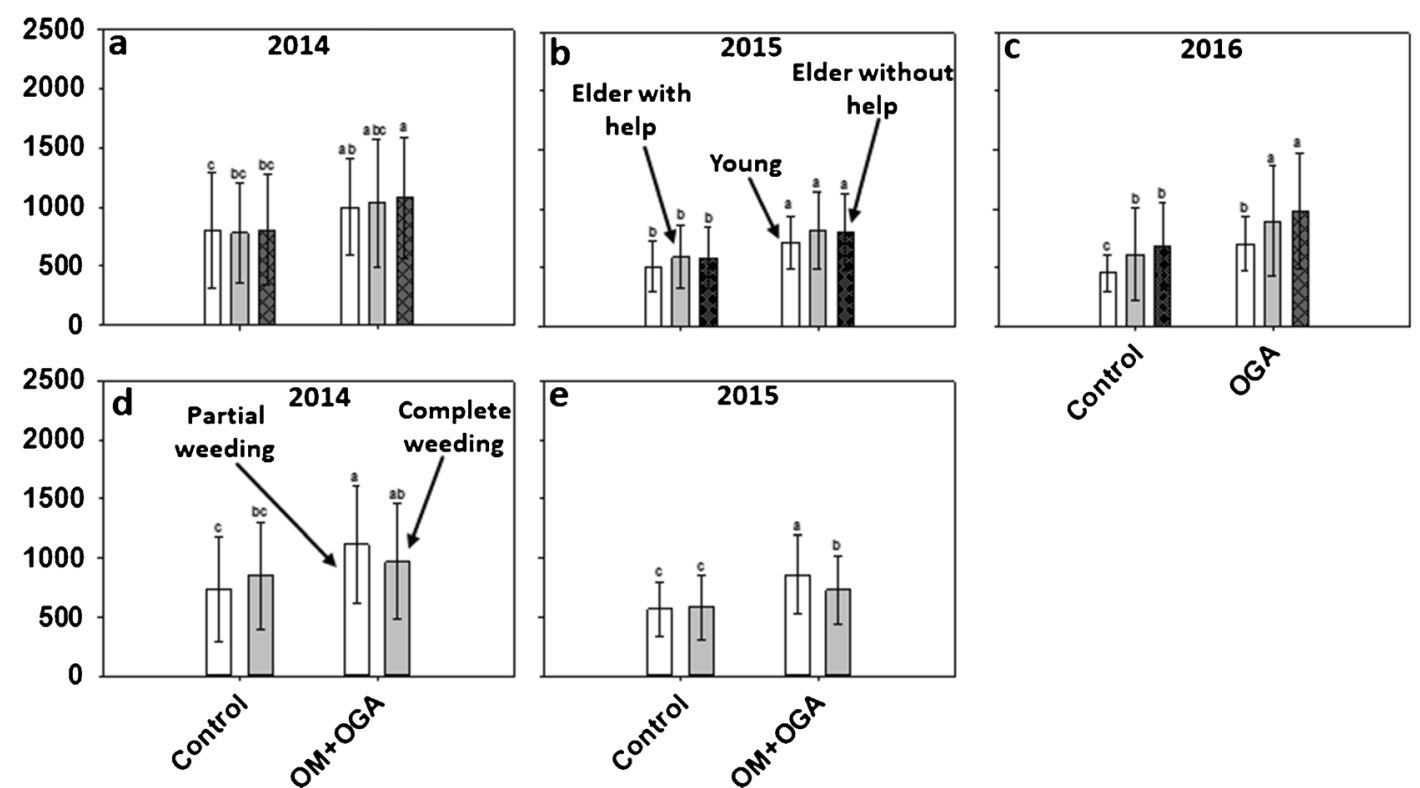

Fig. 8 Pearl millet panicle yield as affected by farmer's age (a, $\mathbf{b}$, and $\mathbf{c}-$ upper graphs) and weed management (d and e-lower graphs) in Maradi and Tillabery regions of Niger Republic. Control $=$ farmer practice, i.e., without fertilization, $\mathrm{OM}=$ organic manure, $\mathrm{Oga}=$ sanitized human

urine. Numbers above indicate the mean treatment yield. Symbols show arithmetic means and error bars indicate standard deviations $( \pm)$, and different letters indicate significance (Tukey test at 5\% level.

season (Sivakumar 1988). In short, Oga application does not only supply nitrogen but also water and thus provides two important factors for crop survival under drought conditions. An additional plus can be the provision of potassium (K) with Oga, since this element is important for cell turgor stabilization and in consequence water use efficiency.

There seems to be a geographical trend with respect to the yield level. The farther south the intervention zone the higher the yield level (Serkin Haussa $\leq$ Safo, Say). This trend can be mainly explained by climatic effects. The average annual rainfall and vegetation period length increase southward; this in turn increases the potential for biomass production. At least in the Maradi region, farmers in the southern intervention zone are perceived as the wealthier ones (source: farmer organization's own database on social stratification), having more financial resources for agricultural inputs like fertilizer and having at the same time easier access to these by the close-by frontier to Nigeria and the markets situated there. In addition, in the south, more "Dallol soils" are present stemming from ancient and recent river valleys, leading, i.a., to groundwater access in lower depth.

In tendency, the relative treatment effect depends on the control yield level. The lower the control yield level the higher the relative treatment effect. This can be mainly explained by the multifold nutrient limitations detected in Sahelian soils (Voortman 2010). In contrast to mineral fertilizers, organic fertilizers are characterized by a multi-nutrient content. However, even when applying those, biomass production is finally limited by water deficiency (Hofer et al. 2017).

Pearl millet yields showed a clear seasonal effect. This is to be expected in the Sahel that is generally characterized with highly variable rainfall and frequent intra-seasonal droughts. Taking the climate station at ICRISAT Sahelian Center (Sadoré) as indicative for the intervention site-Say in SW-Niger, 2015 was a normal year with evenly distributed rainfall; 2014 had below average rainfall and extreme unimodality with peak rainfall in August 2016 was a drought year with a serious pre-season rainfall in April. For the interpretation of the general yield level, it is not sufficient only to consider the total annual rainfall but also its distribution defining the vegetation period and intra-seasonal droughts. Rainfall onset times and peak rainfall can also lead to pest calamities (synchronization of pest and crop cycle), pollen outwash from the open-pollinating pearl millet crop, or massive fungal attack. For the presented trials, rainfall amount and distribution seem to be the major argument behind seasonal yield variability. However, this was not the case for Serkin Haussa in 2014. There, the reasons for a relative high yield are not clear. One could be the June sowing in 2014, while sowing was done later in July in the years 2015 and 2016. Another reason could be the outbreak of shoot 
flies (Atherigona soccata) in 2015 and 2016, which caused significant damages to the pearl millet crop particularly at the Serkin Haussa site and in some trials at Safo.

Averaging the control yields over the 3-year period reflects the information gathered from group interviews in the village of Warzou (Serkin Haussa). Farmers there indicated Jigawa being the preferred pearl millet soil. Gueza, having a slightly more loamy texture, showed relative higher surface shares cropped with sorghum. GuezamiGuezami represents a transition form between the two. Jampali is an extremely sandy soil with the lowest organic matter and chemical fertility status. So, the averaged control yield follows farmers' soil assessment: Jampali $\left(500 \mathrm{~kg} \mathrm{ha}^{-1}\right)<$ GuezamiGuezami $(612 \mathrm{~kg}$ $\left.\mathrm{ha}^{-1}\right)<$ Gueza $\left(647 \mathrm{~kg} \mathrm{ha}^{-1}\right)<$ Jigawa $\left(715 \mathrm{~kg} \mathrm{ha}^{-1}\right)$. The absolute treatment effect shows - with the exception for Gueza-the inverse order (Jampali $346 \mathrm{~kg} \mathrm{ha}^{-1}>$ GuezamiGuezami $253 \mathrm{~kg} \mathrm{ha}^{-1}>$ Jigawa $244 \mathrm{~kg} \mathrm{ha}^{-1}>$ Gueza $169 \mathrm{~kg} \mathrm{ha}^{-1}$ ). Therefore, the general trend depicted in Fig. 7 is supported, taking the soil type as variable. Here, it is interesting to note that on the poorest soil, the treatment effect was highest in the normal rainfall year 2015, while for the other soils, it was always in the drought year 2016. Overall, there rests an unexplained treatment $\times$ rainfall interaction effect.

A village effect is also observed. However, neither soil type counting nor rainfall effects could consistently explain the diverse Oga $(+\mathrm{OM})$ treatment responses. So, there must be other processes and variables involved that have not been collected as data. What has been observed is the influence of age group. Concerning the age group, elderly people without helpers never reach the highest yield spectrum. In contrast, younger people reach higher average and the maximum yields (Fig. 8). Also, an interaction between crop management measures can occur. In our case, partial weeding (in contrast to traditional complete weeding) did reduce the control yield, but together with $\mathrm{OM}+$ Oga produced the highest yields. Partial weeding (i.e., either in stripes or only around the sowing pocket) is a measure to protect young seedlings from wind erosion damage and to reduce workload in a time where available work force is limited. The effect is thought to be season-depending (number and timing of wind erosion events). However, this was not investigated in detail in this study.

From these observations, we can formulate an optimum data set to be collected in order to ease interpretation of heterogeneous on-farm trial results. It would include data on the following: soil (local soil type, texture, $\mathrm{C}_{\mathrm{org}}, \mathrm{N}_{\mathrm{t}}$, Bray1 P $+\mathrm{K}$; pre-seasonal sampling), climate data (daily rainfall, intraseasonal droughts), crop (sowing date, early crop vigor, biomass components at harvest, previously grown crop), pest and fungal attack (locusts, head miners, stem borers, shoot flies, birds at harvest, downy mildews), pollen outwash (coincidence of flowering and high intensity rainfall), farmer (wealth status, age, gender), and field (history, management measures).

\subsection{Lessons for R4D research}

This research profited from a long-term collaboration of stakeholders in agronomic research, i.e., international and national research as well as two farmer federations. The long-term collaboration ( $>10$ years) provided a sound and reliable framework and trust for conducting the relatively large number of on-farm trials on an agronomic innovation. Farmers must have the confidence that the innovation is not setting them at risk. Research stakeholders need trust that the data are collected in the right manner. So, we have a case of mutual dependency that needs to be dealt with in an open manner. Mutual respect and continuous learning on both sites are a prerequisite for success. Therefore, it should be allowed to change the trial protocol between seasons if recent results or pertinent arguments propose it.

Large- $\mathrm{N}$ trials are usually characterized by a nonequilibrated data set and in consequence a lower statistic force. In particular if - on the run - new villages or farmers are introduced in the trial design - point data loss is programmed and needs to be dealt with.

In long-term trials-as the present case-it makes sense to give more freedom to farmers with respect to management of the trial sites. While it is convenient for the researcher to work with ceteris paribus conditions at the beginning in order to reduce heterogeneity in the trials, more variance in later stages improves the potential for site adapted recommendations. E.g., for farmers who practice urea fertilization at booting stage anyway, it does not make sense to apply Oga for a second time. Sometimes farmers make their own observations and then change the "protocol". E.g., it was observed that Oga application reduces certain pest attacks (according to farmers presumably due to the odor). In consequence, timing of the application might be changed, or the application is done for other reasons than nutrient application. Researchers should be aware of this possibility and should not try to block these opportunities, because otherwise they obtain falsely reported data that can hardly be interpreted. Also, these farmer observations can result in other local innovations that benefit smallholder farmers.

Gender aspects deserve a crucial consideration in research for development. They impact on the livelihood of the community through access to inputs, financial resources, and services. More women live in poverty than men and they do take more risks than men. A low-cost innovation is crucial for these women and 
more likely to be successful. Therefore, in this framework, Oga was introduced just for women. The number of women (about 160) who applied the innovation in the very first beginning was encouraging. This number increased to $>230$ in the subsequent trial years. At first, men were more skeptical. They plainly judged Oga as what it is: a low-level innovation adapted particularly to women. However, having seen the results, until present, many men have opted for its application in their farmlands. A difference with respect to inputs, financial resources, and services can exist within the same gender, too. Therefore, the target group should be well defined. In our example, the poorest were targeted, and for these people, innovations should generally exert a low risk, be simple, and effective in order to increase the chance of auto-spreading and adoption.

Large- $\mathrm{N}$ trials will always suffer from the abovementioned shortcomings like non-equilibrated data sets, missing values, and sometimes missing data from whole villages. On the other hand, their advantage is that they deliver data on the potential of an innovation in the real world that is the multitude of factors influencing and decisions taken by the farmer. The valuable outcome is that a more complete picture arises of how and when an innovation can be reasonably recommended. Furthermore, scaling is embedded in the process. Looking at the reality in the field, the researcher-loved ceteris paribus conditions are only another form of bias. And this latter form of bias (with normally much too high projected yield effects) leads to recommendations that do neither contain risk-related nor contextualized how-and-when information. Dealing with subsistence farming conditions, we should use on-station trials only as a first step to understand mechanisms, but large- $\mathrm{N}$ farmer-led on-farm trials in order to evaluate the potential of an innovation in the "real world" and subsequently develop site- and (socioeconomic) environment-adapted recommendations.

\section{Conclusions}

Oga (sanitized human urine) is acceptable as fertilizer component in the pearl millet production system in different ethnic communities of Niger. It is a local, cheap, and easy to use resource available to each and every household, in particular women. In large-N on-farm trials, it showed a consistent performance over years and sites with an average panicle yield increase of about $30 \%$, i.e., $200-300 \mathrm{~kg} \mathrm{ha}^{-1}$. Major determining factors for the pearl millet panicle yield were season (i.e., rainfall amount and distribution), location (i.e., geographical and cultural setting), and local soil type. Additional factors were age group (and resources) and weed management. As a final conclusion, Oga is a low risk, low financial input fertilizer option ready for dissemination on sandy Sahelian sites with low pearl millet yield level. What is currently missing is a detailed financial evaluation of "Oga application" as an auto-innovation. Therefore, such evaluation is recommended for economic utilization of sanitized human urine as fertilizer for higher pearl millet yield in the low chemical fertile farmlands as often observed at women farmlands in Niger.

Supplementary Information The online version contains supplementary material available at https://doi.org/10.1007/s13593-021-00675-2.

Disclaimer The contents are the responsibility of the authors and do not necessarily reflect the views of USAID or the United States Government.

Authors' contribution Our respective contributions are as follows: conceptualization: H. O. Moussa, C. I. Nwankwo, and L. Herrmann; methodology: H. O. Moussa, A. M. Aminou, B. I. G. Haussmann, and D. A. Stern; investigation: H. O. Moussa, C. I. Nwankwo, A. M. Aminou, and B. I. G. Haussmann; writing-original draft: H. O. Moussa and C. I. Nwankwo; writing-review \& editing: H. O. Moussa, C. I. Nwankwo, A. M. Aminou, D. A. Stern, B. I. G. Haussmann, and L. Herrmann; funding acquisition: H. O. Moussa, A. M. Aminou, and B. I. G. Haussmann; resources: H. O. Moussa, A. M. Aminou, B. I. G. Haussmann, and L. Herrmann; and supervision: H. O. Moussa, A. M. Aminou, B. I. G. Haussmann, and L. Herrmann.

Funding Open Access funding enabled and organized by Projekt DEAL. This study was made possible through the generous support of McKnight Foundation's Collaborative Crop Research Program (www.ccrp.org) and the American People, provided to the Feed the Future Innovation Lab for Collaborative Research on Sorghum and Millet through the United States Agency for International Development (USAID). Program activities are funded by the United States Agency for International Development (USAID) under Cooperative Agreement No. AID-OAA-469 A-1300047.

Data availability The datasets generated during and analyzed during the current study are available in the Zenodo repository, https://zenodo.org/ record/4071827\#.X33QgO2xU1I, with DOI 10.5281/zenodo.4071826.

\section{Declarations}

Ethics statement The human urine used in this study was strictly for research purpose and was collected from the local farmers under FUMA Gaskiya through the local animators.

Conflict of interest The authors declare no competing interests.

Open Access This article is licensed under a Creative Commons Attribution 4.0 International License, which permits use, sharing, adaptation, distribution and reproduction in any medium or format, as long as you give appropriate credit to the original author(s) and the source, provide a link to the Creative Commons licence, and indicate if changes were 
made. The images or other third party material in this article are included in the article's Creative Commons licence, unless indicated otherwise in a credit line to the material. If material is not included in the article's Creative Commons licence and your intended use is not permitted by statutory regulation or exceeds the permitted use, you will need to obtain permission directly from the copyright holder. To view a copy of this licence, visit http://creativecommons.org/licenses/by/4.0/.

\section{References}

Aune JB, Ousman A (2011) Effect of seed priming and micro-dosing of fertilizer on sorghum and pearl millet in Western Sudan. Exp Agric 47:419-430. https://doi.org/10.1017/S0014479711000056

Badiane A, Faye A, Yamoah CF, Dick R (2001) Use of compost and mineral fertilizers for millet production by farmers in the semiarid region of Senegal. Biol Agric Hortic 19:219-230. https://doi.org/10. 1080/01448765.2001.9754926

Bationo A, Christianson C, Baethgen W, Mokwunye A (1992) A farmlevel evaluation of nitrogen and phosphorus fertilizer use and planting density for pearl millet production in Niger. Fertilizer Research 31:175-184. https://doi.org/10.1007/BF01063291

Blackden M, Canagarajah RS, Klasen S, Lawson D (2003) Gender and growth in Africa: evidence and issues. World Bank, Washington, DC, pp 1-18

Chen M. (2008) Women and employment in Africa: a framework for action, background document commissioned by the Danish Foreign Ministry for the Second Conference of the Africa Commission, Harvard University, WIEGO Network: 44

Diarra M, Monimart M (2006) Landless women, hopeless Women? Gender, land and decentralisation in Niger. International Institute for Environment and Development, London, UK: 143

Doss CR (2001) Designing agricultural technology for African women farmers: lessons from 25 years of experience. World Dev 29:20752092. https://doi.org/10.1016/S0305-750X(01)00088-2

Geiger L (2017) Einfluß von Bodeneigenschaften auf den Perlhirseertrag bei Anwendung der Saatkugeltechnologie. University of Hohenheim, Germany, Master thesis

Germer J, Addai S, Sauerborn J (2011) Response of grain sorghum to fertilisation with human urine. Field Crop Res 122:234-241. https:// doi.org/10.1016/j.fcr.2011.03.017

Guglielmino CR, Viganotti C, Hewlett B, Cavalli-Sforza LL (1995) Cultural variation in Africa: role of mechanisms of transmission and adaptation. Proc Natl Acad Sci 92:7585-7589. https://doi.org/ 10.1073/pnas.92.16.7585

Herrmann L, Haussmann BIG, van Mourik T, Traoré PS, Oumarou HM, Traoré K, Ouedraogo M, Naab J (2013) Coping with climate variability and change in research for development targeting West Africa: need for paradigm changes. Science et Changements Planétaires/Sécheresse 24:294-303. doi:https://doi.org/10.1684/sec. 2013.0401

Hofer D, Suter M, Buchmann N, Lüscher A (2017) Severe water deficit restricts biomass production of Lolium perenne L. and Trifolium repens $\mathrm{L}$. and causes foliar nitrogen but not carbohydrate limitation. Plant Soil 421:367-380. https://doi.org/10.1016/j.agee.2014.02.034

Karak T, Bhattacharyya P (2011) Human urine as a source of alternative natural fertilizer in agriculture: a flight of fancy or an achievable reality. Resour Conserv Recycl 55:400-408. https://doi.org/10. 1016/j.resconrec.2010.12.008
Karanam P, Vadez V (2010) Phosphorus coating on pearl millet seed in low P Alfisol improves plant establishment and increases stover more than seed yield. Exp Agric 46:457-469. https://doi.org/10. 1017/S0014479710000608

Kirchmann H, Pettersson S (1995) Human urine - Chemical composition and fertilizer use efficiency. Fertilizer Research 40(1994):149-154. https://doi.org/10.1007/BF00750100

Klaij MC, Vachaud G (1992) Seasonal water balance of a sandy soil in Niger cropped with pearl millet, based on profile moisture measurements. Agric Water Manag 21:313-330. https://doi.org/10.1016/ 0378-3774(92)90053-Y

Michels K, Armbrust DV, Allison BE, Sivakumar MV (1995) Wind and windblown sand damage to pearl millet. Agron J 87:620-626. https://doi.org/10.2134/agronj1995.00021962008700040003x

Nordin A, Niwagaba C, Jönsson H, Vinnerås B (2013) Pathogen and indicator inactivation in source-separated human urine heated by the sun. Journal of water, sanitation and hygiene for development 3:181-188. https://doi.org/10.2166/washdev.2013.174

Nwankwo CI (2019) Seedball technology development for subsistenceoriented pearl millet production systems in Sahelian West Africa. $\mathrm{PhD}$ thesis University of Hohenheim, Germany

Nwankwo CI, Blaser SR, Vetterlein D, Neumann G, Herrmann L (2018) Seedball-induced changes of root growth and physico-chemical properties - a case study with pearl millet. J Plant Nutr Soil Sci 181:768-776. https://doi.org/10.1002/jpln.201800059

Powell J, Ikpe F, Somda Z, Fernandez-Rivera S (1998) Urine effects on soil chemical properties and the impact of urine and dung on pearl millet yield. Exp Agric 34:259-276. https://doi.org/10.1017/ S0014479798343069

Raj SN, Shetty NP, Shetty HS (2004) Seed bio-priming with Pseudomonas fluorescens isolates enhances growth of pearl millet plants and induces resistance against downy mildew. Int J Pest Manag 50:41-48. https://doi.org/10.1080/09670870310001626365

Reddy K, Visser P (1993) Late planting effects on early versus late pearl millet genotypes in Niger. Exp Agric 29:121-129. https://doi.org/ $10.1017 / \mathrm{S} 0014479700020469$

Safilios-Rothschild C (1985) The persistence of women's invisibility in agriculture: theoretical and policy lessons from Lesotho and Sierra Leone. Econ Dev Cult Chang 33:299-317. https://doi.org/10.1086/ 451462

Satyavathi CT, Bharadwaj C, Brahmanand P (2010) Role of farm women in agriculture: lessons learned. Gend Technol Dev 14:441-449. https://doi.org/10.1177/097185241001400308

Sivakumar M (1988) Predicting rainy season potential from the onset of rains in southern Sahelian and Sudanian climatic zones of West Africa. Agric For Meteorol 42:295-305. https://doi.org/10.1016/ 0168-1923(88)90039-1

Voortman RL (2010) Explorations into African land resource ecology: on the chemistry between soils. In: plants and fertilizers. PhD thesis Vrije Universiteit, Amsterdam, Netherlands

World Reference Base IWG (2015) World Reference Base for soil resources 2014, updated in 2015: International soil classification system for naming soils and creating legends for soil maps. World Soil Resources Reports 106:192

Yamba B (1993) Les ressources ligneuses et problèmes d'aménagement forestier dans la zone agricole du Niger III. Thèse de doctorat Université Michel de Montaigne. Bordeaux, France

Publisher's note Springer Nature remains neutral with regard to jurisdictional claims in published maps and institutional affiliations. 